\title{
PERANCANGAN DAN PENERAPAN SISTEM INFORMASI E- MARKET HIBURAN UNTUK MEMENUHI KEBUTUHAN HAJATAN BAGI MASYARAKAT KABUPATEN INDRAMAYU BERBASIS ONLINE
}

\author{
Ahmad Lubis Ghozali' ${ }^{1}$, Ahmad Rifa'i' ${ }^{2}$ Iryanto $^{3}$ \\ 1,2,3 Program Studi Teknik Informatika \\ Politeknik Negeri Indramayu Jl. Raya Lohbener Lama No. 08 Indramayu 45252 Fax / Tlp. (0234) 5746464 \\ E-mail : ${ }^{1}$ lubis@polindra.ac.id, $\underline{2 a h m a d r i f a i 716 @ g m a i l . c o m, ~}{ }^{3 \text { iryanto.math@gmail.com }}$
}

\begin{abstract}
ABSTRAK
Hajatan merupakan acara yang sangat istimewa bagi setiap orang. Kemeriahan hajatan merupakan suatu hal yang sering diadakan guna memberikan rasa sukacita dalam hajatan. Hiburan merupakan salah satu komponen dalam hajatan untuk memeriahkan suatu acara hajatan, tetapi penyewaan hiburan terkadang menjadi kendala seperti tanggal dan bulan yang tidak cocok serta harga sewa dan fasilitas yang sering berubah-ubah. E-Market merupakan salah satu bentuk media yang memasarkan layanan kepada pelanggan menggunakan media web. E-Market menjadi sangat dibutuhkan karena kemudahan akses dan murahnya penyebaran informasi. Mulai dari smartphone hingga perangkat desktop sekarang sudah mendukung kemudahan akses karena aplikasi dibangun dengan teknologi responsive desain. Aplikasi e-market hiburan untuk kebutuhan hajatan ini merupakan solusi bagi permasalahan sewa hiburan di suatu hajatan agar setiap orang yang akan hajatan tidak terlalu kesulitan dalam melakukan penyewaan suatu hiburan.
\end{abstract}

Kata Kunci : E-Market, Sistem Informasi, Hajatan, Hiburan, Penyewaan, Responsive, Web.

\begin{abstract}
Celebration is a very special event for everyone. The celebration of celebration is something that is often held to give a sense of joy in celebration. Entertainment is one component in the celebration to enliven a celebration event, but rental entertainment is sometimes an obstacle such as a date and month that is not suitable and rental prices and facilities that often change. E-Market is one form of media that markets services to customers using web media. E-Market is very much needed because of the ease of access and the cheap distribution of information. From smartphones to desktop devices now support easy access because applications are built with responsive design technology. The entertainment e-market application for celebration needs is a solution to the problem of entertainment rental in a celebration so that everyone who will celebrate is not too difficult in renting an entertainment.
\end{abstract}

Keywords: E-Market, Information Systems, Celebration, Entertainment, Rental, Responsive, Web 


\section{PENDAHULUAN}

Kemajuan teknologi sekarang ini semakin terus berkembang. Informasi yang realtime dalam lintas duniapun sudah dapat diakses dengan mudah menggunakan komputer, smartphone dan lain sebagainya yang terhubung dengan internet. Kemudahan akses informasi tersebut terus dikembangkan sehingga memunculkan ide-ide baru untuk membuat sistem pengolahan informasi.

Hajatan merupakan acara yang sangat istimewa bagi siapapun. Kemeriahan hajatan merupakan unsur penting dalam hajatan. Menyewa tempat, hiburan, dan lain sebagainya adalah suatu kebiasan yang biasa dilakukan oleh pihak yang mempunyai hajatan agar tamu yang hadir dapat lebih bersukacita merayakan hajatan tersebut.

Sebaliknya, melakukan penyewaan tempat, hiburan, dan lain sebagainya merupakan hal yang cukup merepotkan yang harus dilakukan oleh pihak yang mempunyai hajatan. Tanggal dan bulan yang tidak cocok, harga dan fasilitas yang sering berubahubah merupakan hal-hal yang sering kali menjadi hambatan antara penyedia hiburan dengan pihak yang mempunyai hajatan, sehingga itu membuat ketidaksesuaian dengan keinginan dan harapan dari pihak yang mempunyai hajatan.

Pengelolaan informasi yang membantu antara pihak yang mempunyai hajatan dengan pihak penyedia hiburan sangat diperlukan. Dengan dibuatnya pengelolaan informasi tersebut diharapkan dapat membantu untuk mempermudah pihak yang mempunyai hajatan untuk menyelenggarakan hajatannya. Oleh karena itu penulis berharap dengan mengambil penelitian ini diharapkan dapat memudahkan penyewaan hiburan untuk suatu acara hajatan.

\section{TEORI DAN METODE}

Menurut Turban (2003) seperti yang dikutip oleh Saleh (2016), SDLC adalah metode pengembangan sistem tradisional yang digunakan sebagian besar organisasi saat ini. SDLC adalah kerangka kerja (framework) yang terstruktur yang berisi prosesproses sekuensial di mana sistem informasi dikembangkan.

Sedangkan menurut Azhar Susanto (2004) seperti yang dikutip oleh Saleh (2016) menyatakan bahwa SDLC adalah salah satu metode pengembangan sistem informasi yang populer pada saat sistem informasi pertama kali dikembangkan. Model waterfall adalah salah satu metode dalam SDLC. Seperti dikutip oleh Ayu Langening Tyas (2016), Model waterfall merupakan model klasik yang sederhana dengan aliran sistem yang linier. Output dari setiap tahap merupakan input bagi tahap berikutnya (Kristanto, 2004). Artinya pada tiap-tiap tahap dalam model waterfall harus dilakukan secara maksimal karena tidak adanya pengerjaan yang sifatnya paralel.

\section{A. Metode Pengumpulan Data}

1. Observasi

Penulis melakukan pengamatan dari hasil datadata yang didapatkan melalui kuisioner-kuisioner dan data-data dari Dinas Kebudayaan dan Pariwisata Kabupaten Indramayu yang dikemudian penulis menyimpulkannya ke dalam proses yang terstruktur untuk di implementasikan ke dalam sistem aplikasi.

\section{Studi Pustaka}

Penulis mencari bahan-bahan atau referensi yang dapat digunakan sebagai referensi penulis untuk merancang sistem aplikasi yang dapat digunakan oleh masyarakat dalam bertransaksi. Referensi tersebut baik dari website-website sejenis dengan penelitian penulis seperti website tokopedia, bukalapak, dan facebook.

\section{HASIL PENELITIAN}

Penelitian ini menghasilkan sebuah aplikasi emarket hiburan untuk kebutuhan hajatan. Aplikasi ini dapat digunakan untuk mempromosikan hiburan bagi pihak-pihak yang mempunyai hiburan. Aplikasi ini juga dapat digunakan untuk menginformasikan tentang suatu acara hajatan sehingga setiap orang yang masih kerabat dekat pembuat hajatan dapat mengetahui ada hajatan di mana lokasi hajatannya serta dapat menginformasikan hiburan apa saja yang ada pada hajatan tersebut dengan catatan penyewaan hiburan dilakukan dalam aplikasi ini.

Penulis menyimpulkan aplikasi e-market hiburan untuk kebutuhan hajatan yang telah dibuat adalah aplikasi yang digunakan untuk media informasi, komunikasi, dan transaksi antara pihak yang akan hajatan dengan pihak penyedia hiburan untuk kebutuhan hajatan.

Implementasi desain interface dan program merupakan tahap untuk mengimplementasikan desain yang telah dirancang pada bab sebelumnya. Setiap desain halaman/form/popover dibuat dengan menggunakan dreamweaver. Antarmuka atau interface merupakan cara untuk memudahkan pengguna/user dalam melakukan aktivitas dalam aplikasi. Berikut beberapa tampilan interface dalamaplikasi e-market hiburan untuk kebutuhan hajatan. 


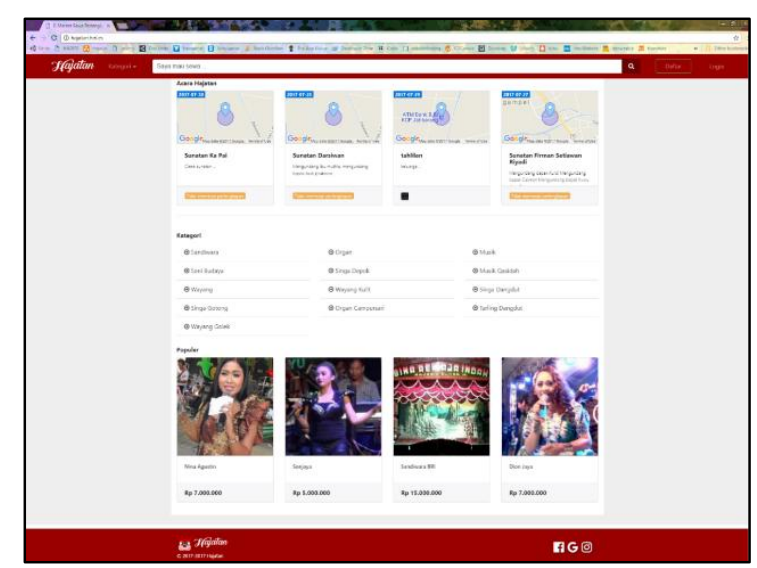

Gambar 1. Tampilan Halaman Awal

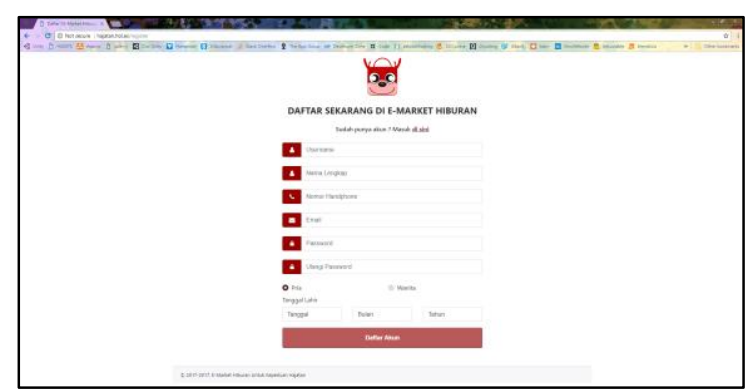

Gambar 2. Tampilan Halaman Register

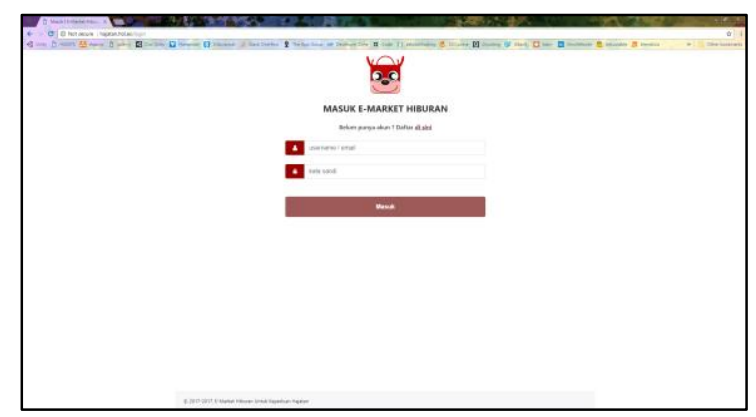

Gambar 3. Tampilan Halaman Login

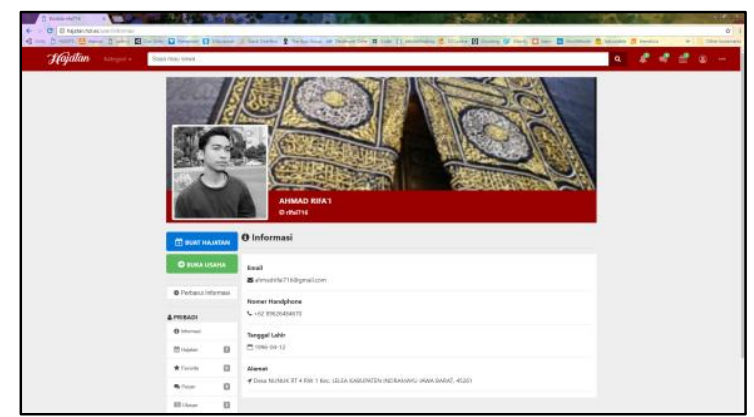

Gambar 4. Tampilan Halaman Informasi User

\section{KESIMPULAN}

Kesimpulan yang didapat setelah mengumpulkan, mengolah, menganalisa, mengimplementasi serta melakukan pengujian aplikasi adalah sebagai berikut.
1. Aplikasi ini dirancang dengan cara mengumpulkan data-data melalui metode observasi dan studi pustaka, kemudian setelah data-data terkumpul dilakukan proses desain sistem.

2. Aplikasi ini dibuat dalam bentuk responsive desain sehingga dapat diakses dengan tampilan yang baik dengan menggunakan smartphone ataupun komputer/PC (Desktop).

3. Proses transaksi diterapkan dengan melibatkan dua user yaitu pihak penyewa dan pihak penyedia hiburan yang dimana user penyewa sebelum melakukan penyewaan hiburan harus membuat suatu hajatan.

4. Pengujian aplikasi dilakukan dengan menggunakan Black-Box Testing yang telah diuji oleh user melalui kuisioner dan hasil dari pengujian yang didapatkan melalui kuisioner tersebut menyatakan aplikasi e-market hiburan untuk kebutuhan ini amat baik dengan presentase nilai $85,75 \%$.

\section{Saran}

Aplikasi e-market hiburan untuk kebutuhan hajatan ini tidak luput dari kekurangan. Oleh karena itu penulis menyarankan kepada pengembang selanjutnya agar dapat mempertimbangkan beberapa saran yang diberikan supaya aplikasi e-market hiburan untuk kebutuhan hajatan ini semakin lengkap dan baik. Saran-saran tersebut antara lain sebagai berikut.

1. Pengumpulan data-data untuk tahap perancangan aplikasi dapat ditingkatkan dengan cara melakukan wawancara langsung dan terstruktur kepada pihak penyedia hiburan supaya data yang didapatkan lebih valid.

2. Dapat dibuat dalam bentuk mobile application sehingga akan lebih memudahkan akses bagi pengguna aplikasi.

3. Proses transaksi dapat ditingkatkan menjadi transaksi yang terkomputerisasi dari mulai melakukan pemesan hiburan sampai transaksi transfer uang. Sehingga semua transaksi dapat terkontrol oleh sistem.

4. Dapat ditambahkan pengujian menggunakan White-Box Testing agar sistem dapat lebih baik lagi dan optimal untuk diakses.

\section{Daftar Pustaka}

[1] Ghozali, A. L. and Bunga, M.S., 2017. Implementasi Sistem Business Intelligence Terhadap Rekap Nilai Perkuliahan 
Menggunakan Metode Online Analitycal Processing (OLAP), Semnasteknomedia Online, 5(1), 1-2,.

[2] Suehring, Steven dan Janet Valade. 2013. PHP, MySQL, Javascript \& HTML5 all-in-one for Dummies. John Wiley \& Sons Inc. Hoboken. New Jersey.

[3] Susanto, Deni. 2015. Perancangan Sistem Informasi Laporan Penjualan Pada Pt Kinnara Mitra Selaras. Tanggerang : STMIK Raharja.

[4] Tandusan, Chevy F. 2015. Jurnal Riset Bisnis dan Manajemen. Vol.3, No.2.

[5] Ghozali, A. L., Prakoso, M. I., \& Muin, A. A. 2018. Penerapan Sistem Pakar Diagnosa Demam Berdarah Dengue Menggunakan Certainty Factor Methods. Jurnal INSYPRO (Information System and Processing), 2(2). 